\title{
AC 2009-1046: TEACHING COLLABORATIVE ENGINEERING DESIGN IN A DISTRIBUTED ENVIRONMENT THROUGH EXPERIENTIAL LEARNING
}

\section{Xiaobo Peng, Prairie View A\&M University}

Xiaobo Peng is an Assistant Professor in the Department of Mechanical Engineering at Prairie View A\&M University. He received his PhD in Mechanical Engineering from University of Missouri-Rolla in 2005. His research interests include CAD/CAM, haptics, solid modeling, virtual reality, and virtual product design. Dr. Peng is the member of ASEE and ASME.

Katie Grantham Lough, Missouri University of Science and Technology

Assistant Professor, Interdisciplinary Engineering Department, Missouri University of Science and Technology

Benjamin Dow, Missouri University of Science and Technology

Assistant Chair of Extended Studies, Engineering Management and Systems Engineering Department, Missouri University of Science and Technology 


\title{
Teaching Collaborative Engineering Design in a Distributed Environment through Experiential Learning
}

\begin{abstract}
This paper presents a collaborative project conducted by Prairie View A\&M University (PVAMU) and Missouri University of Science and Technology (MS\&T) to jointly develop collaborative engineering design instructional projects. The projects integrate engineering design, design methodology, and project management in the teaching of multidiscipline courses at two universities. Collaboration tool Teamcenter Community (TcC), and CAD tool NX are utilized in the collaboration. The collaborative design projects have been implemented in Fall 2006 and in Spring 2008. Students from two universities teamed up as groups to work on the projects. This paper presents the implementation of Teamcenter Community and the utilization of it in the collaborative design projects. Challenges and lessons learned through the collaboration are also discussed.
\end{abstract}

\section{Introduction}

Global collaboration has become necessary in industry because of the globalization of the economy in the 21 st Century. The new economy demands that today's engineers are able to work in a distributed, interdisciplinary, problem-based, and technology-enhanced environment ${ }^{1}$. Product Lifecycle Management (PLM) has been adopted by many industries which enables the global collaboration. As defined by Grieves ${ }^{2}$, PLM is "an integrated, information-driven approach comprised of people, process/practices, and technology to all aspects of a product's life, from its design through manufacture, deployment and maintenance-culminating in the product's removal from service and final disposal." With such a PLM system the members of a design team in geographically dispersed locations are able to interact with each other effectively in the collaborative design process. These trends have challenged college education to develop engineering students with the necessary skills for collaborative design in a geographically distributed environment.

To meet this emerging need, Prairie View A\&M University (PVAMU) and Missouri University of Science \& Technology (MS\&T, formerly University of Missouri-Rolla) have jointly developed collaborative engineering design instructional projects and implemented these collaborative design projects in the teaching of engineering design courses at two universities. Two pilot projects have been carried out in Fall 2006 and Spring 2008. The students at both universities teamed up to work on the collaborative design projects, by dividing up the project tasks among different team members. The members of each team consisted of students from both universities. The projects were funded by GM Foundation through PACE program (Partners for the Advancement of Collaborative Engineering Education), which is a consortium established by GM, EDS, Sun Microsystems, Siemens PLM Solutions, HP, Autodesk, and their global operations.

The objectives of the collaboration projects are: 
1. To teach students the necessary skills and technologies of conducting collaborative engineering design in a distributed environment through experiential learning;

2. To teach students to design system, components, and processes through real-life problems;

3. To develop students the teamwork and communication skills.

It is infeasible for most of the engineering programs to create a new course to teach students collaborative design due to the already heavy program schedule. This paper presents a more feasible method to infuse collaborative engineering design into current curricula through practical design projects without significant changes of the program schedule. In addition, the projects train students how to use the PLM software Teamcenter Community and CAD software NX3 from Siemens PLM Solutions, which are the same tools used in many industries such as GM. It will benefit the students to be more competitive in the job market.

\section{Related Work}

Many research papers ${ }^{3-6}$ have reported that integration of collaboration activities using on-line tools can enhance learning, reduce the sense of isolation, increase participants' learning motivation, and improve students' social interaction skills. However, researches ${ }^{7-10}$ also found that there are practical challenges associated with such collaborations, including communication anxiety, time pressures, differences in the level of student intake, differences of resources, and differences in information technology platforms. From the social and psychological perspective, Hughes et al. ${ }^{6}$ provided a comprehensive survey of literatures to address how to establish the most effective on-line collaboration. The paper summarized four aspects of effective collaboration, including: (1) getting students to understand the value of collaboration; (2) establishing comfort with the technology used in the collaborative environment; (3) building comfort and trust among students and between instructor and students; and (4) creating a rich online social environment. Many universities have developed collaborative design program in the geographically dispersed environment in their curricula ${ }^{1,9,11-18}$. Most of the projects were implemented in the senior/graduate level and two-semester long courses. By deploying the pilot projects, we are seeking to develop guidelines for integrating collaborative engineering design in regular one-semester engineering curricula.

\section{Collaborative Design Infrastructure}

\section{$\underline{\text { Teamcenter Lab at PVAMU }}$}

As the host University of the collaborative projects, PVAMU is in charge of deploying the PLM software Teamcenter Community. The projects have served as a catalyst for PVAMU to build the infrastructure of collaborative engineering design. A state-of-the-art collaborative design laboratory is under development with the support of PACE program and College of Engineering at PVAMU since the beginning of 2006. The hardware and software are available at PVAMU including:

Hardware: two High-end Sun servers (x2100); one HP large format printer; thirty two high-end engineering workstations; Tandberg video conference and distance learning system 
Software: Unigraphics NX3; Altair Hyperworks 7.0; ANSYS; Teamcenter Community 5.2; Video and audio conferencing software

\section{Teamcenter Community Website}

Teamcenter Community ( $\mathrm{TcC}$ ) enables team members geographically dispersed to collaborate and share 2D and 3D visual data, documents, and presentations. A TcC website was designed for the collaborative projects at PVAMU. The website consists of homepages for instructors and student teams. As shown in Fig. 1, the instructor homepage is restricted to be accessed by the instructors and teaching assistants. The major component of the homepage is the "Professor's Announcement". This is where the project assignments, tutorials, instructions, and other timely announcements can be posted. The "Announcement" is made as a "pushdown list" which can be automatically distributed to all the team sub-websites. The "Team Sub-website Links" on the homepage provides a convenient way for the instructors to access each team's webpage.

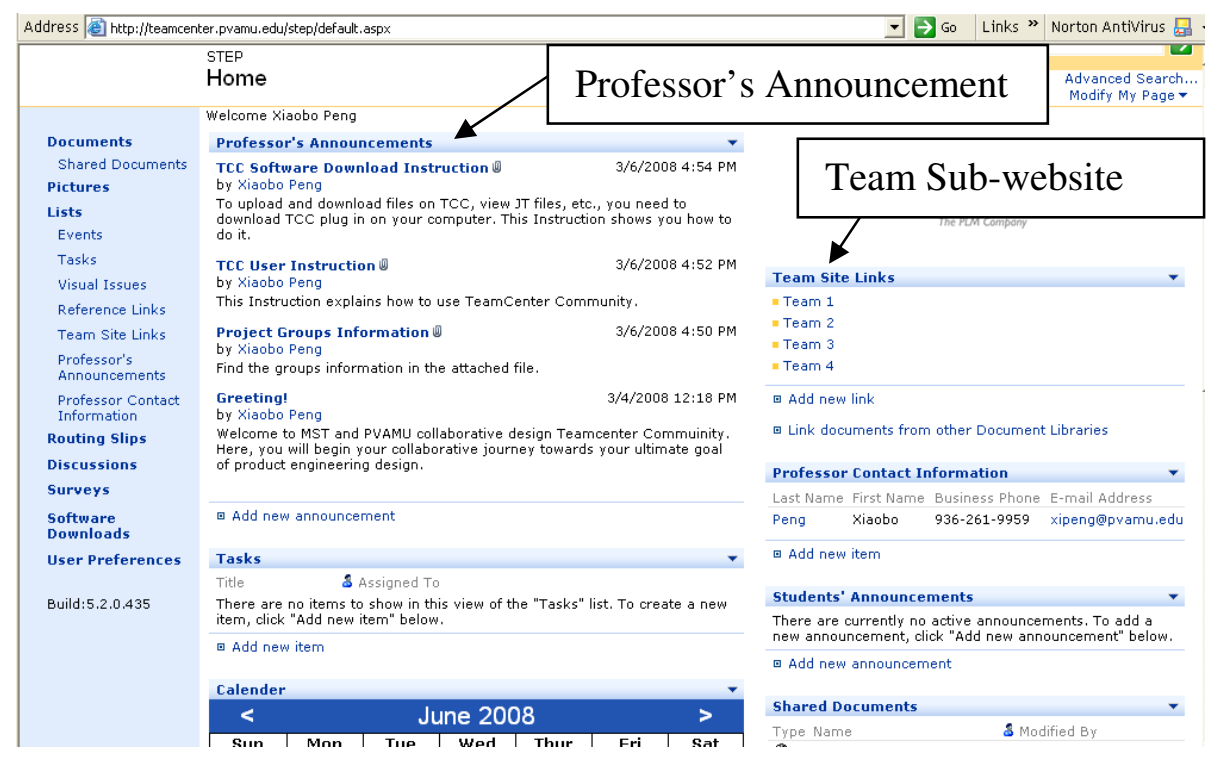

Figure 1. TcC instructor homepage

Team websites were designed for each team as shown in Fig. 2, which are logged in directly by designated team members. It contains the following components:

(1) Professor's Announcement: This is distributed from the parent site (instructor homepage).

The students can not edit it.

(2) Tasks: Students use it to distribute the tasks to each team member.

(3) Announcement: The students can post news, project status, and other short information that they want to share with their team members.

(4) Shared Documents: This is mostly often used component where students can upload NX part files, 3D assemblies, and documents, etc.

(5) Contact Information: Members can post their names and contact information here.

(6) Links: The links lists are used to post hyperlinks to webpage of interest to the team.

(7) Calendar: It is used to post information about dates that are important for the team.

(8) Iseries Viewer: It is a tool embedded in $\mathrm{TcC}$ that provides $2 \mathrm{D} / 3 \mathrm{D}$ visualization, review and markup capabilities. It is enabled by the CAD-neutral JT format which can be created from 
all major CAD applications. Students can perform the synchronizing design, review and markup within the TcC by open the JT file of an assembly or a single CAD model as shown in Fig. 3. It is a very powerful tool for collaborative design.

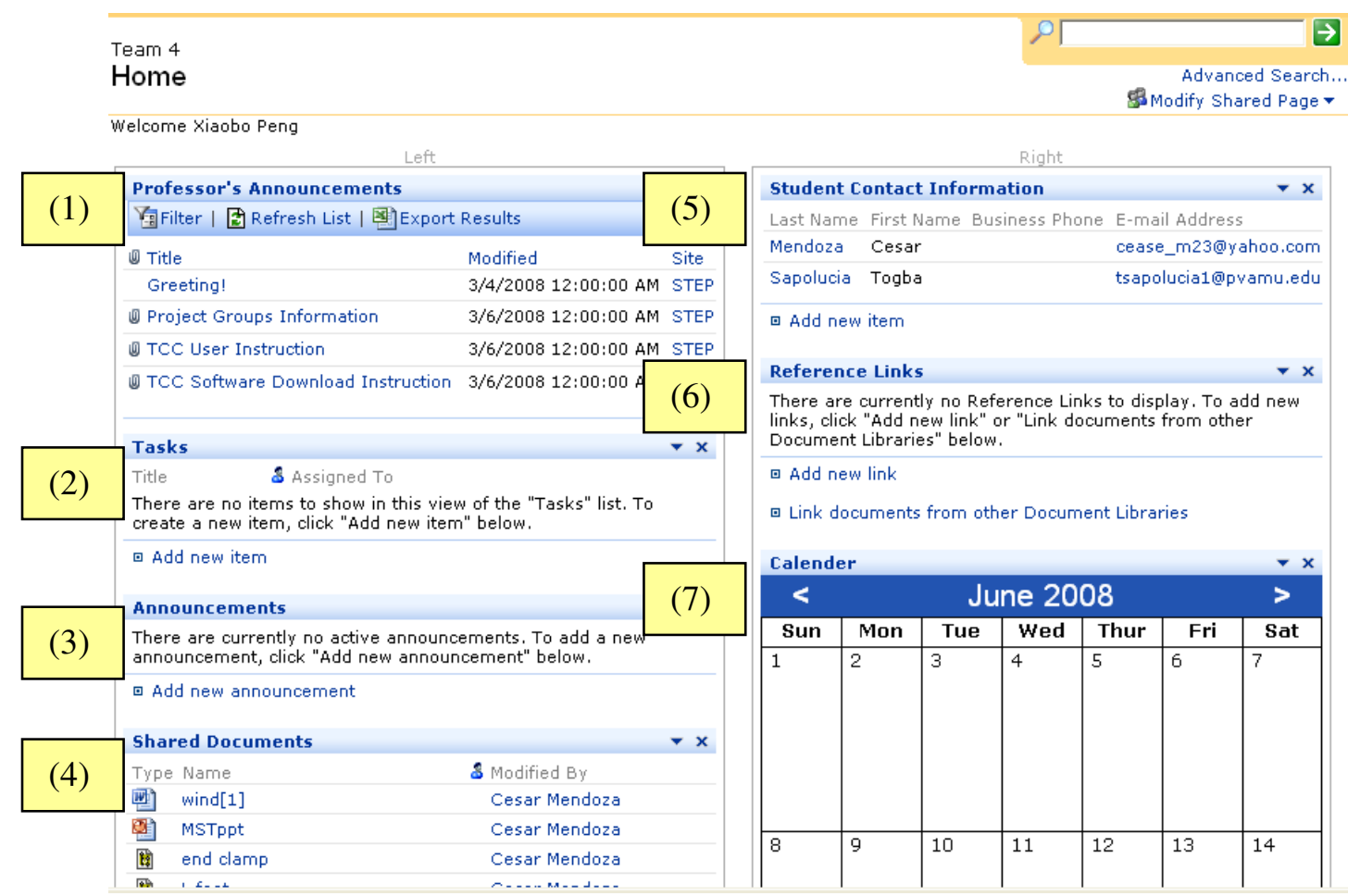

Figure 2. TcC homepage for teams

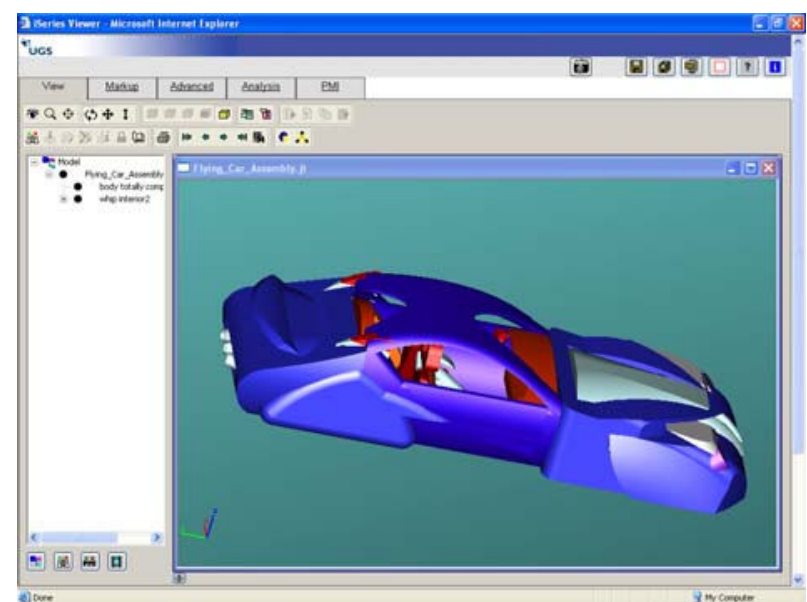

Figure 3. Visualize 3D CAD model in TcC using Iseries View

\section{Client Software Download}

To fully utilize the functions of Teamcenter Community such as visualizing jt 3D models, uploading the files to the server, downloading documents, and performing seamless editing of Microsoft Office documents etc., the plug-in needs to be downloaded and installed on the client computers. In the public computer labs at both PVAMU and MS\&T, students do not have the 
Administrator privileges to install the software. The Administrator must be involved in this process. For instance, at MS\&T the request to install software must be submitted to IT three months in advance. This caused some delay for the students to start using TcC at MS\&T. Some students found that it was more convenient to use their personal computers to access TcC.

Tutorials on how to install $\mathrm{TcC}$ client software and how to use $\mathrm{TcC}$ were developed and distributed to students. Students were trained in the class on how to use TcC. It was reported by students that most of the functions of TcC are easy to learn such as Shared Document, Calendar, Tasking, Announcement etc. Because students had little knowledge on project management, the functions of $\mathrm{TcC}$ related to project management such as routing slips were seldom used. Also due to the small scale of the collaborative project, the advantages of using project management functions do not appear appealing to students.

\section{Pilot Project 1}

The first pilot project was carried out in Fall 2006. The collaborative design projects were implemented in the freshman level course MCEG1213 "Creative Engineering" at PVAMU and the senior/graduate level course ME363 "Principles and Practices of Computer-Aided Design" at MS\&T. Both courses were offered in Mechanical Engineering. The instructors from two universities designed three pre-defined topics, including backhoe, tandem bicycle, and folding bicycle. MS\&T and PVAMU students were required to team up as groups and complete a conceptual design of a new product. In addition, the students were requested to address material selection, manufacturing concern, and cost analysis of the product.

There were 22 students enrolled in ME363 at MS\&T and 14 students enrolled in MCEG1213 at PVAMU respectively. Each group consisted of four students. Students had six weeks to complete the project. Each team was required to submit a report and give a presentation. All the documents including NX3 part files, the final assembly file, reports and PowerPoint slides were required to be uploaded to the Teamcenter Community website. To incent students to use $\mathrm{TcC}$, the active and sufficient usage of TcC was applied as one of the criteria to grade the project. The detail implementation and results of the pilot project 1 are described in the paper ${ }^{19}$.

Lessons learned in pilot project 1 includes: 1) six weeks were very limited for collaborative project; 2) misunderstanding and miscommunication among the team members were not perceived and resolved promptly which caused a delay of the project; 3 ) the group composition was not effective as students had different level of technical skills (freshman at PVAMU collaborating with graduate/senior students at MS\&T).

\section{Pilot Project 2}

The second pilot project was conducted in Spring 2008. The collaborative design projects were implemented in two junior/senior level design courses, MCEG 4043 "Machine Design II" in Mechanical Engineering at PVAMU and IDE 215 "Junior Design Project" in Interdisciplinary Engineering at MS\&T, and one project management course, EMgt 461 "Global Project Management" in Engineering Management at MS\&T. Based on the experience learned from the first pilot project, several changes were made: 
(1) From the previous project it was found that students lack skills in communication and project management which has been a critical obstacle to the success of the collaboration. The second project involved a professor and a group of students in Engineering Management assisting with planning, scheduling, and monitoring the progress.

(2) The previous design projects did not explore students' skills in analyzing and evaluating the design using CAE tools. The second project involved students with similar technical level and multidisciplinary technical background in engineering design, design methodology, and project management.

(3) The second pilot project started earlier which gave students ten weeks to complete the project.

(4) A subject was designed which required more collaboration not only within the same team but also among different teams.

\section{Collaborative Design Project}

The on-going Solar House project at MS\&T was adopted as the collaborative design project. MS\&T has been doing research to develop a Solar Thermal Electric Panel (STEP) Hybrid Roof System since 2005. The idea was that electricity and hot water were to be acquired for the home using the same area on the roof, rather than the traditional solar home setup of separate roof areas for each system. The water was heated while simultaneously cooling the solar panels. This inturn increases the efficiency of the panels themselves. In pilot project 2, the students were assigned to collaboratively design, build, and test a modular Solar Thermal Electric Panel for potential residential renewable power applications. The design of the modular system requires the integration of four subsystems, i.e. solar panels, thermal systems, modular system, and attachment system.

Each group was assigned a subsystem of the modular Solar Thermal Electric Panel (STEP) roof system to design, analyze, and integrate. The final design must be an assembly that integrates functionally with the other design teams' components of the STEP system. The design tasks of each subsystem are described as below:

(1) Solar Panels - A solar panel to power the STEP system must be selected that meets the performance requirements of the house, based on previous solar houses, and also powers and integrates with the thermal subsystem design. The solar panel must be conducive to modular roof panel assembly.

(2) Thermal System - A roof mounted water heating system must be designed that utilizes the excess radiant energy from the solar panels to heat the fluid inside the thermal system. This fluid needs to reach temperatures high enough to provide hot water heating for the solar house. Also the thermal system will serve as a cooling mechanism for the solar panels to increase their efficiency.

(3) Modular System - The components of the solar panel and thermal system must be contained in a module. A serie of modules may be used to cover the roof of the house and provide the necessary power and hot water heating to the home.

(4) Attachment System - Each module must be able to attach to one another to comprise an entire roof system. Also, the collection of modules must attach to the roof of a solar house. 
There were twenty nine students participated in this project as illustrated in Fig. 4. The Solar Panels team included four students in the IDE 215 class. The other three teams consisted of one MS\&T student in the "Global Project Management" class, four or five MS\&T students in the "Junior Design Project" class, and three PVAMU students in the "Machine Design II" class. The project management students in each team were in charge of managing and coordinating the project. The "Junior Design Project" students took the role of concept and detail design, test, and building the prototype. The PVAMU students created the CAD models and analyzed the performance based on the design of MS\&T students.

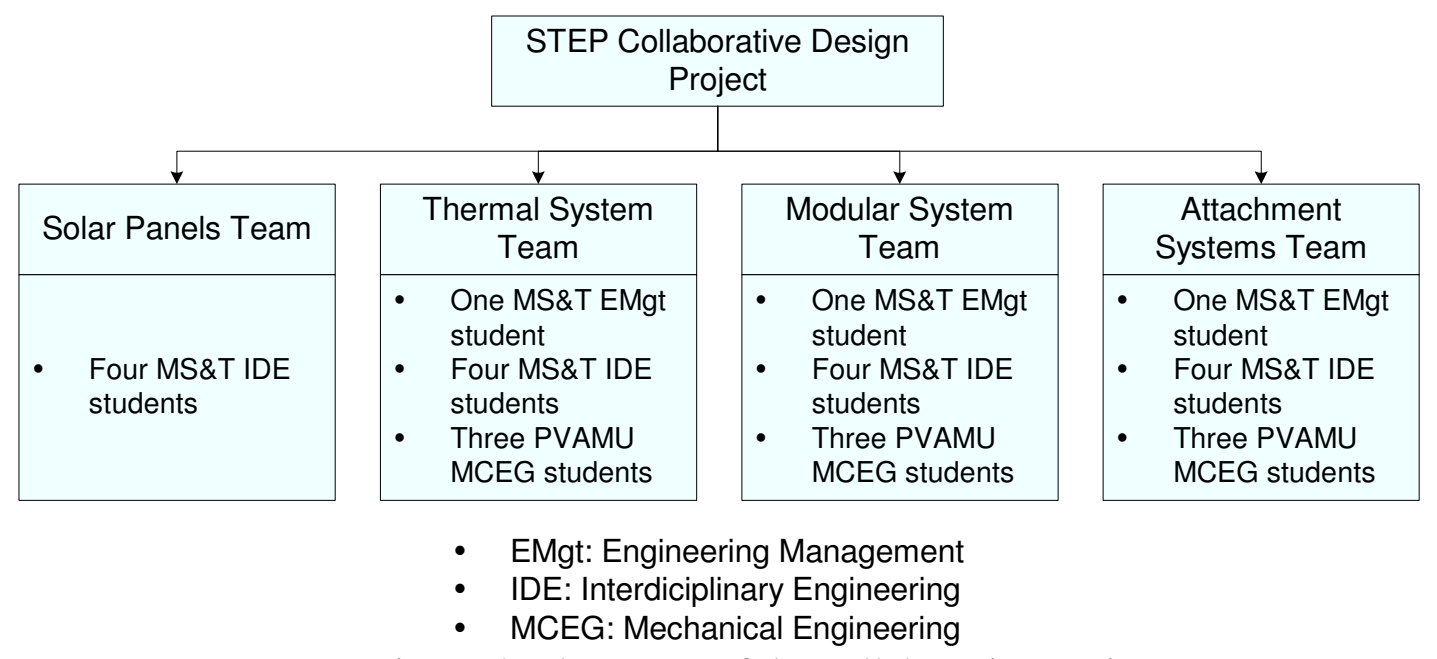

Figure 4. The teams of the collaborative project

\section{Collaboration Activities}

It is observed in this project that thorough communication among the team members is the critical key to the success of the collaborative design. Besides Teamcenter Community, various collaborative tools such as Video Conference, Email, and Instant Messenger etc. were utilized to enable the communication between the team members.

Teamcenter Community was used extensively by students, and was the primary means of transferring Unigraphics part files and data. Utilizing $\mathrm{TcC}$, each group member was able to express questions and concerns, receive answers, and post their completed part files. In addition, $\mathrm{TcC}$ allowed group members to view relevant project files and a project timeline, both of which assisted in the timely completion of the final project.

It has been suggested that an initial face-to-face meeting will significantly enhance the trust and familiarity among team members and the willingness to collaborate ${ }^{6}$. However, it was not feasible to have a face-to-face meeting for our students due to the time and cost constraints. The video conferencing system was used at the initial stage of the project to get the team members from two campuses know each other and discuss the proposal. The video conferencing system was also used throughout the project to give lectures, discuss the proposal, review the design, and present the final results. Figure 5 shows that Professor Dow at MS\&T was giving a lecture on Project Management to PVAMU students using video conferencing. In addition to video conferencing, Email, Messenger, and Phone etc. were used. The instructors did not impose any 
use of collaboration tools or collaboration activities other than TcC. Different groups had different opinions on using the collaboration tools. Some groups met weekly using Messenger. Some groups did not have regular meeting instead they called each other when they found necessary. Some groups used email exclusively for exchanging ideas without calling each other.

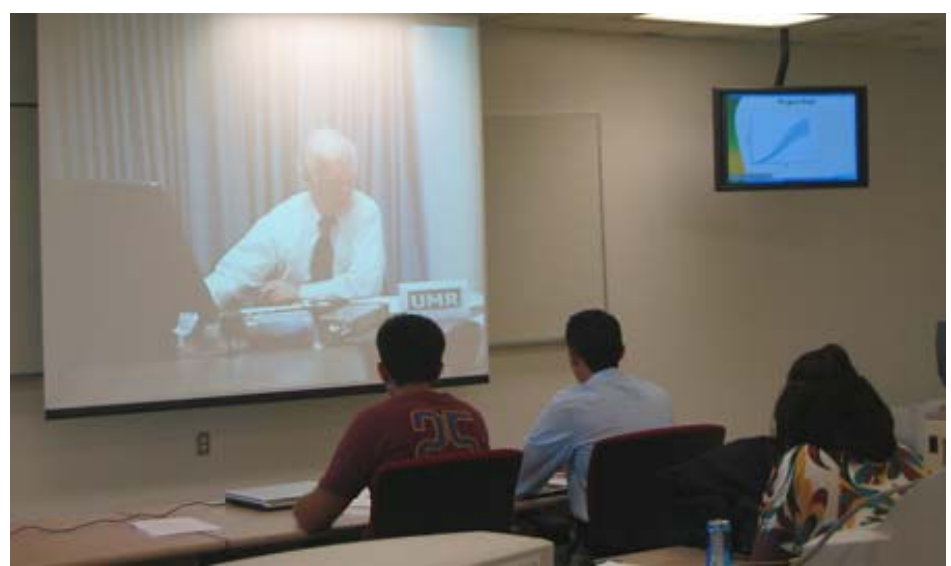

Figure 5. Teaching project management via video conferencing

\section{$\underline{\text { Design Results }}$}

The designs completed by each team were reported in detail in our previous paper ${ }^{20}$. The attachment system is presented here as an example. The rack system is composed of two rails manufactured by UniRac. It will be secured to the roof via L-Brackets, as shown in Fig. 6(a). The Unigraphics NX software was used to analyze specific parts of the Unirac rail system. The analysis result is shown in Fig. 6(b).

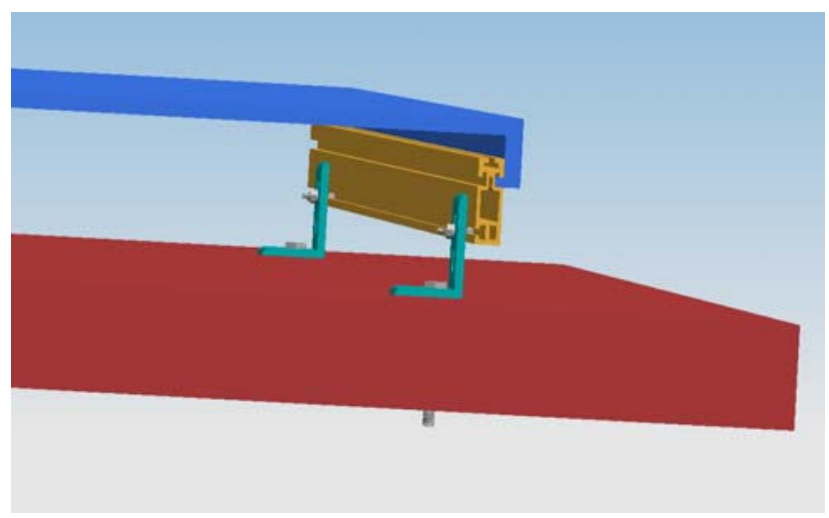

(a)

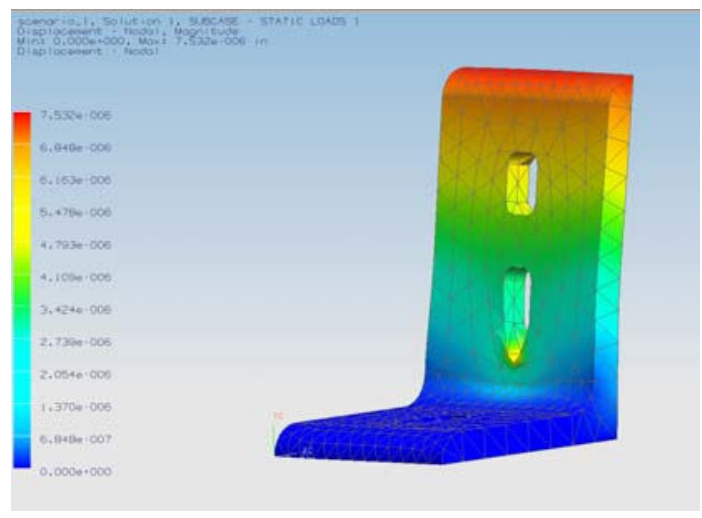

(b)

Figure 6. (a) The CAD model of the rack system; (b) The load analysis of the Unirac rail system

\section{$\underline{\text { Presentation Competition }}$}

The final presentation competition was held at the end of semester. Students presented their projects simultaneously and interactively with their partners from two sites through video conferencing system as shown in Fig. 7. WebEx was used to share and present PowerPoint slides. The presentations were evaluated by the panel of judges which consists of faculty and 
industry representatives from GM and Altair Engineering. Although the competition was very close, the team responsible for the attachment system was the declared winner. All the teams were awarded prizes.

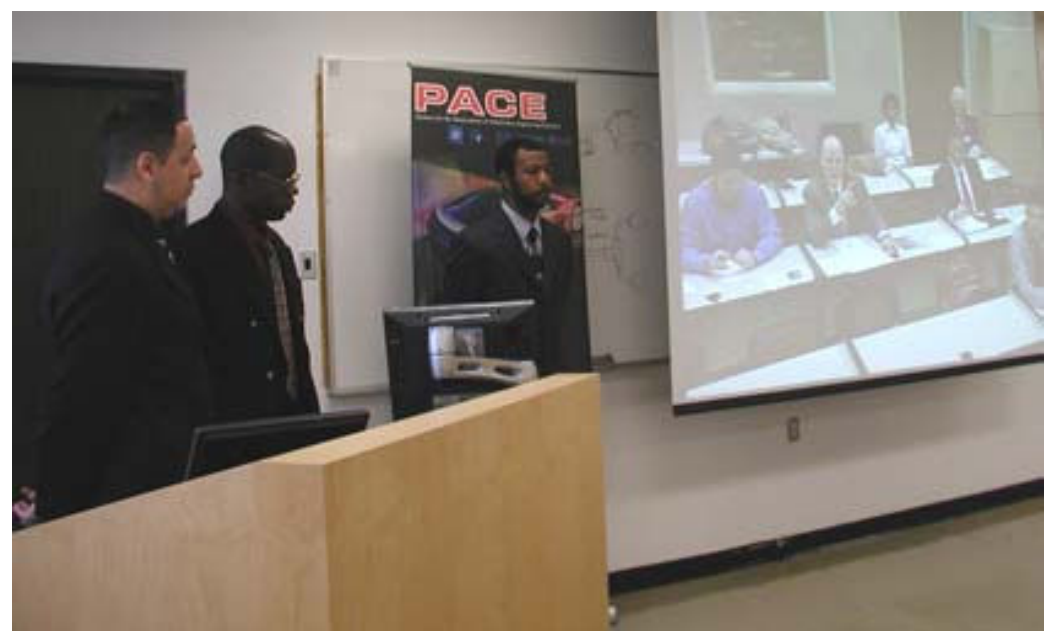

Figure 7. Final presentation competition using video conferencing

\section{Evaluation}

The students were required to report their evaluations, suggestions, and recommendations in their final reports. The following comments are some of the feedback from students:

- "The usage of the Teamcenter Community was a good way to make sure all of the files were delivered in a timely manner."

- "The idea of collaborating with another University is good one. Apart from sharing ideas, there is also a scope for socializing."

- "This project was a wonderful experience for us. This project helped us grow as future professionals. While doing this project we learned to trust our teammates. We polished our communication skills in a real world setting."

- "Regular and frequent communication between team members proved to be an essential component of this team's success in assembling a complete backhoe loader model."

- "In the end, teammates came to the conclusion that team work is important, but it is hard work."

\section{Challenges and Lessons Learned}

From experience gained by conducting two pilot collaborative design projects, it is found that challenges exist in integrating collaborative design into engineering curricula. The challenges and lessons were found as below:

(1) To implement the $\mathrm{TcC}$ at the host institution, it is essential to secure the adequate manpower support and the commitment from IT department early. A solid infrastructure of PLM solution is required in order to conduct collaborative design. Teamcenter Community is proved to be an efficient tool. Its implementation needs comprehensive support of both hardware and software. The authors suggest starting the deployment of the $\mathrm{TcC}$ at least 6 months before the collaboration. 
(2) IT Administrators should be involved as early as possible at all participating institutions. In order to make $\mathrm{TcC}$ accessible to all the participating campuses, the plug-in needs to be downloaded and installed on the client computers. This process can take much longer and can be more complicated than you imagine. For instance, at MS\&T the request to install any software in computer labs must be submitted to IT three months in advance. We did not realize this until the project started. This caused some delay for the students to start using TcC.

(3) It is essential to ensure that the same versions of the software are used by the teams. If not, how to make the data compatible should be taken into account when planning the project. In pilot project 2, PVAMU has NX3 and MS\&T uses NX5. The students at PVAMU encountered problems while using the models created by MS\&T partners.

(4) It is important to identify the answers for the following questions before initiating the collaboration: which courses will adopt the collaborative projects? Do the schedules at the participating universities fit each other? What would be the appropriate design subjects for collaboration without adding too much burden on the current curricula to the students?

(5) Thorough communication among the team members is the critical key to guaranteeing the success of the collaborative design in a distributed environment. Compared with pilot project 1 , the communication, planning, and the quality of the collaboration in pilot project 2 were enhanced because of the integration of project management. The team composition is also a factor of ensuring effective communication. In pilot project 1, the communication in the groups which had two PVAMU and two MS\&T students were more effective than those groups which had one PVAMU and three MS\&T students.

\section{Conclusion and Future Work}

Two pilot projects have been carried out by MS\&T and PVAMU to integrate collaborative engineering design projects using Teamcenter Community in engineering design courses at two universities. The implementation of Teamcenter Community is described in this paper. Various collaborative tools, including Teamcenter Community, Video Conference, Email, and Instant Messenger etc., were utilized to assist the communication between the team members. It was observed that the integration of project management in the collaborative projects enhanced the communication, planning, and the quality of the collaboration. We have discussed the challenges of integrating collaborative design into engineering curricula. By implementing the collaborative design projects in the teaching of design courses, the students learned how to effectively perform collaborative product design using different techniques and CAD systems in a distributed environment and to understand the collaborative nature of product design and related issues. Future work will focus on researching the factors that affect the effectiveness of integrating collaborative design projects into engineering curricula. Evaluation and assessment of the collaboration activities will be carry out in the future.

\section{Acknowledgements}

The authors would like to acknowledge the support from the PACE Program/GM Foundation in providing funding, hardware, software, and technical support for this project. 


\section{Bibliography}

1. Koszalka, T. A., Wu, Y., and Davidson, B. D., 2008, "Evaluating a Cross-Institutional Collaborative Engineering Design Course within a Distributed Educational Environment," in the Proceedings of $12^{\text {th }}$ Annual Global Chinese Conference on Computers in Education, East Lansing, Michigan, May 4 8.

2. Grieves, M., 2006, Product Lifecycle Management: Driving the Next Generation of Lean Thinking, McGrawHill, 2006, p. 39.

3. Clark, J., 2000, "Collaboration Tools in Online Learning Environments," ALN Magazine, 4(1).

4. Hiltz, S. R., Coppola, N., Rotter, N., Turoff, M., and Benbunan-Fich, R., 2000, "Measuring the Importance of Collaborative Learning for the Effectiveness of ALN: A Multi-measure Multi-method Approach," ALN Journal, $5(2)$.

5. Lowyck, L. and Poysa, J., 2001, "Design of Collaborative Learning Environments," Computers in Human Behavior, 17(5-6), pp. 507-516.

6. Hughes, S. C., Wichersham, L., Ryan-Jones, D. L., and Smith, S. A., 2002, "Overcoming Social and Psychological Barriers to Effective On-line Collaboration," Educational Technology \& Society, 5(1), pp. 86-92.

7. Bishop, P., Cox, B., Fothergill, R., Kyle, J., Lawson, D., Mitchell, M., Rathbone, J., Stone, E., and Thelwall, M., 2001, "Inter-institutional Collaboration on Easing the Transition to University," LTSN Maths and Stats Newsletter, 1(1), pp. 5-8.

8. de Bruyn, L., 2004, "Monitoring Online Communication: Can the Development of Convergence and Social Presence Indicate an Interactive Learning Environment?" Distance Education, 25(1), pp. 67-81.

9. Wang, X., Dannenhoffer III, J. F., Davidson, B. D., and Spector, J. M., 2005, "Design Issues in a CrossInstitutional Collaboration on a Distributed Education Course," Distance Education, 26(3), pp. 405-423.

10. Scripture, J. D., 2008, "Recommendations for Designing and Implementing Distributed Problem-Based Learning," American Journal of Distance Education, 22(4), pp. 207-221.

11. Herder, P. M., Turk, A. L., Subrahmanian, E., and Westerberg, A. W., 2002, "Communication and Collaborative Learning in a Cross-Atlantic Design Course," in the Proceedings of 2002 World Conference on Educational Multimedia, Denver, Colorado, June 24-29.

12. O’Brien, W., Soibelman, L., and Elvin, G., 2003, "Collaborative Design Processes: An Active- and ReflectiveLearning Course in Multidisciplinary Collaboration," Journal of Construction Education, 8(2), pp. 78-93.

13. Dennis, T. W. and Fulton, R. E. 2004, "Undergraduate Distributed Collaborative Engineering Project Using CAD, CAE and PLM Tools," in Proceedings 2004 ASEE Southeastern Section Annual Meeting, Auburn, Alabama, April 4-6.

14. Bohn, J. H. and Anderl, R., 2005, "A First Transatlantic Course on Collaborative Engineering and Product Data Management," presented at PACE Annual Forum, Mexico City, Mexico, July 27-30.

15. Jensen, C. G., Dean, C. , Bohn, J. H., and Marshall, J., 2005, "Using Collaboration and PLM Tools to Link Remote Capstone Team Members," presented at PACE Annual Forum, Mexico City, Mexico, July 27-30.

16. McCammon, J. B., Brooks, B. W., and Jensen, C. G., 2006, "Hosting/Participating in Global Collaborative PACE Projects," presented at PACE Annual Forum, Provo, Utah, July 24-29.

17. Hinds, T. J. and Lloyd, J. R., 2006, "Teamcenter Tools Collaboration Project," presented at PACE Annual Forum, Provo, Utah, July 24-29.

18. Anderson, J., Eastein, M., Nielsen, B., and Rochow, T., 2006, "Virtual Engineering Design Collaboration: A Journey into Uncharted Territory," presented at PACE Annual Forum, Provo, Utah, July 24-29.

19. Peng, X., Leu, M. C., and Niu, Q., 2008, "Integration of Collaborative Engineering Design Using Teamcenter Community in Mechanical Engineering Curricula," Product Realization: A Comprehensive Approach, edited by Mileta M. Tomovic and Shaoping Wang, Springer Science+Business Media, Inc.

20. Peng, X., Lough, K. G., and Dow, B., 2008, "Integrating Engineering Design, Prototyping, and Project Management Using PLM Tools,” PACE Global Annual Forum, Detroit, MI, July 28-August 1. 